\title{
Eyelid Papilloma
}

National Cancer Institute

\section{Source}

National Cancer Institute. Eyelid Papilloma. NCI Thesaurus. Code C4061.

A papillomatous lesion that arises from the eyelid. The representative example is eyelid squamous cell papilloma. 